\title{
LAS ELECCIONES BRASILEÑAS DE 1994: ¿CONTINUIDAD O CAMBIO?
}

\author{
Alfredo A. Gugliano y Ariel Jerez*
}

\section{INTRODUCCION}

El triunfo electoral del socialdemócrata Fernando Henrique Cardoso fue saludado por la opinión pública internacional como una cambio de rumbo de la dinámica política brasileña. Este optimismo se fundamentaba en la propuesta electoral que el propio Cardoso había definido, durante la campaña, como el problema a superar: Brasil no es un país subdesarrollado, es un país injusto.

Sin entrar a analizar el trasfondo político-ideológico de este diagnóstico, enunciado por alguién que conoce en profundidad este debate, la dinámica política brasileña de los últimos años muestra determinados procesos y comportamientos que plantean serias reservas sobre la viabilidad de la propuesta socialdemócrata elegida por el electorado brasileño.

Cardoso optó para ganar estas elecciones con una coalición electoral -ahora gubernamental- con partidos conservadores que, llevando décadas en el poder del estado, nunca han mostrado la menor intención de realizar alguna de las reformas necesarias para superar el problema anteriormente apuntado. El Partido da Frente Liberal (PFL) y el Partido Trabalhista Brasileiro (PTB) son partidos herederos de la tradición política oligárquica que ha marcado el desarrollo del estado brasileño y, en concreto, son los responsables por el actual diseño del sistema político (1). En el caso del PFL, la gran mayoría de sus diputados fueron miembros de la Alianza Renovadora Nacional (ARENA), partido que dio sustentación a los gobiernos militares y que, ya en democracia, participaron en los gobiernos Sarney y Collor; presidente este último que recibió su apoyo hasta los últimos momentos de su destitución (2).

(*) Alfredo A. Gugliano es Licenciado en Historia en la Universidad Federal de Rio Grande do Sul (UFRS) y doctorando en Sociología en la Universidad Complutense de Madrid (UCM). Ariel Jerez es investigador becario el Departamento de Ciencia Política y de la Administración (II) de la Universidad Complutense de Madrid (UCM).

(1) Mainwaring (1991 y 1993) analiza los problemas que presenta la combinación de un sistema presidencialista con un sistema electoral mayoritario, que no cuenta con cláusulas de exclusión ni mecanismos que garanticen la fidelidad partidaria. La lógica fragmentadora derivada de esta estructura institucional, agravada por determinados hábitos en la relación ejecutivo-legislativo heredados de la fases populista y autoritaria, potencia un comportamiento individualista entre los políticos que compromete gravemente la eficacia de sus funciones, tanto en el plano de la representación como en el de la qobernabilidad.

(2) Antonio Carlos Magalhaes, gobernador del Estado de Bahia y uno de los principales dirigentes del Partido da Frente Liberal (PFL) declaraba meses antes del impeachment: "El que diga que el impeachment es posible, está mintiendo al pueblo. Tiene 103 años y nunca fue usado. Es una farsa que no está ni siquiera regulada" (traducción autores, Veia, 30/12/1992)
A lo largo de la transición, el continuo reacomodo de los partidos conservadores en nuevas siglas daba cuenta de la crisis vivida por el bloque conservador, que tiene dos motivos básicos. Primero, la incapacidad mostrada para poner en marcha un proyecto económico coherente de estabilización y ajuste. Sus intereses políticos y electorales están ligados históricamente a la dinámica desordenada de expansión del aparato del estado y del gasto público, sobre la que articulan las redes clientelísticas que le garantizan su hegemonía en el ámbito legislativo. Segundo, esta dinámica predatoria fue exhibiendo, gracias a la libertad política y de información del nuevo contexto democrático, unos grados de corrupción que daban cuenta del nivel de deterioro en que se encuentra el aparato de estado brasileño.

Como consecuencia de esta crisis y de la movilización y organización vivida en la sociedad civil a lo largo del proceso de transición, se empezaba a configurar un espacio para propuestas políticas alternativas (Gugliano, 1994).

La reestructuración del bloque conservador cerró el paso a estas propuestas. El Partido da Social Democracia Brasileira (PSDB) fue clave en este proceso, que se llevó a cabo durante el gobierno interino de I. Franco - sucesor de Collor-, cuando Cardoso ocupaba la cartera de Hacienda, y se viabilizó por medio de un plan antiinflacionario, el Plan Real, cuyo éxito inicial revirtió todas expectativas de voto, que hasta el mes de mayo indicaban como favorito a Luis Inacio Lula da Silva, candidato del Partido dos Trabalhadores (PT) (3).

Para abordar este proceso, nos planteamos en este artículo dos objetivos. Primero, reconstruir la campaña electoral a partir de ciertos datos y procesos que señalan un hilo de continuidad en cuanto a estilos de hacer política se refiere. Segundo, realizar un análisis de los resultados electorales, lo que nos dará pie para realizar un comentario final sobre las perspectivas del gobierno Cardoso.

(3) El tan polemizado carácter electoralista del plan económico quedó claro en el que fue conocido como "Caso Ricúpero". Rubens Ricúpero, que sustituyó a Cardoso en la Cartera de Hacienda cuando este decidió disputar la Presidencia, declaraba off the record durante grabaciones de un programa periodístico en la Rede Globo, que él era quién estaba haciendo ganar las elecciones a Cardoso y que no tenía "escrúpulos" en ocultar datos negativos del plan. Captada su declaración a través de antenas parabólicas, el Ministro no tuvo otra alternativa que dimitir (Veja, 3/8/1995). 


\section{LA CAMPAÑA PRESIDENCIAL: SINTOMAS DE CONTINUIDAD}

En este apartado, examinamos en un primer momento uno de los núcleos del discurso de la campaña socialdemócrata: el perfil intelectual del candidato. Posteriormente, reconstruimos diversos acontecimientos y analizamos algunos datos que a nuestro entender cuestionan esta idea de cambio tan celebrada por la opinión pública.

En Brasil ha existido siempre una activa participación de los intelectuales en la vida política, que en muchos casos se ha concretado en compromisos orgánicos con partidos políticos y movimientos sociales. A partir de la transición democrática, un número significativo de estos intelectuales transitan de universidades y centros de investigación a los gobiernos y parlamentos (Pecaut. 1990).

La contradicción entre el político y el científico planteada por Weber parece adecuada para comprender las actuales posiciones del presidente electo. Algo que se pudo contemplar incluso en la campaña electoral cuando éste, frente a un público de empresarios, pide sin mucho remordimiento: "olviden lo que yo escribr̂". Frase llena de simbolismos, esta invitación al olvido representa la imagen de un intelectual que subordina su condición de científico a los requerimientos del poder: la ética de la responsabilidad se impone a la ética de la convicción.

El perfil de científico del candidato fue utilizado como un medio para obtener votos. En una clara utilización de la técnica y la ciencia como ideologia, en la campaña electoral Cardoso fue presentado no solamente como un buen político, sino como un intelectual que estudió la realidad brasileña y que, por tanto, poseía la capacidad técnica para ofrecer soluciones para los problemas del pais. El objetivo de esta contraposición estaba claro: dirigir la disputa electoral para el campo de las "credenciales educativas" entre el intelectual Cardoso y los demás (4). Este es un aspecto importante especialmente si consideramos las argumentaciones de autores como Alain Touraine, que vinculan la posibilidad de éxito de Cardoso a su condición de sociólogo internacionalmente reconocido (5).

Respecto a esta cuestión se pueden realizar dos observaciones. En primer lugar la condición de intelectual, a no ser que sea utilizada como instrumento ideológico, no representa una cualidad política en sí misma, pues tratándose de un proceso electoral es inevitable que los candidatos que son científicos presenten diferentes proyectos políticos que van más allá de su vocación profesional.

En segundo lugar, debemos destacar que el "conocimiento técnico", que en Brasil fue utilizado como un slogan de Cardoso, no representa necesariamente una propuesta democrática, visto que éste tanto puede cumplir una función emancipadora como puede ser un instrumento

(4) Esto fue utilizado en contraposición a Lula, de profesión tornero en el sector automotriz. El dos de agosto de 1994, en la cena de apoyo que el mundo de la cultura daba a la candidatura de Cardoso, una invitada desempolvaba un viejo prejuicio, ampliamente recogido por la prensa, al declarar que no se podía dudar en la elección entre un "fontanero y el Sartre Brasileño".

(5) Esta linea argumental ha sido compartida en diversos articulos aparecidos en España en el periodico El País, por intelectuales socialdemócratas como A.O.Hirschman, M. Castells o J. Castañeda (Jerez, 1995). de preservación de las desigualdades sociales. En el caso referido, la condición de intelectual de Cardoso representó, de modo simbólico, una concepción conservadora de la ciencia: la contraposición entre aquél que detenta el conocimiento contra los que se juzga que no saben nada. Por tanto, no se trata de cuestionar si el mencionado sociólogo puede ser un buen o un mal político, para retomar la contraposición weberiana, sino la forma en que se empleó su condición de intelectual durante la campaña electoral.

En relación al desarrollo de la campaña electoral, se hizo evidente la asimetría de recursos existentes entre las fuerzas enfrentadas, que se puso de manifiesto en el uso de los medios de comunicación, un verdadero bombardeo propagandístico (Lima y Bustani, 1995) (6). La estrategia de Cardoso estaba basada, además de la ya comentada instrumentalización de la imagen del intelectual y de la nueva moneda, en otra reveladora directriz: la desvinculación de Fernando Henrique Cardoso de sus socios de coalición. En los espacios televisivos dedicados a la disputa presidencial nunca apareció el candidato a vicepresidente, que era designado por el PFL; en los reservados a las proporcionales aparecían los candidatos de los respectivos partidos sin mencionar referencia alguna a la coalición. La intención de ocultamiento, a la vez que exitosa, era patente para los observadores atentos.

La campaña para las elecciones de octubre de 1994 tuvo como punto de arranque las Caravanas da Cidadania organizadas por el PT y protagonizadas por Lula entre abril de 1993 y julio de 1994. Estos inusuales viajes de un candidato presidencial al Brasil profundo, imprimieron un considerable empuje a la campaña del PT lo que se reflejó en los primeros sondeos de intención de voto, que situaban a Lula como favorito (7).

La primera respuesta que el bloque conservador dio a esta situación partió del ámbito legislativo: el 20 de septiembre de 1993 se aprobó en el parlamento la modificación de la legislación electoral. A todas luces diseñada para minar los recursos organizativos del PT, la ley contó con tres dispositivos: 1) se facilitó la forma de contribución económica de las empresas a los candidatos al mismo tiempo que prohibía la contribución de los sindicatos; 2) prohibió el uso de megafonía en la vía pública así como el tradicional boca-de-urna, que consiste en el reparto de propaganda en la puerta de los colegios electorales, considerada como la más importante forma de propagada del PT; 3) se reformuló el formato de los espacios políticos gratuitos en la televisión, prohibiendo la utilización de imágenes externas, no filmadas en el estudio de grabación, en los espacios gratuitos de los candidatos, algo que también fue otra marca registrada en las anteriores campañas del PT.

Con todo, como ya mencionamos antes, la campaña cambia de rumbo a partir de que, en julio de 1995, entró en circulación la nueva moneda, el Real. Se produjo así un movimiento de aglutinación de las diferentes élites politicas y económicas en apoyo a Cardoso y contra Lula, "el candidato

(6) Dimenstein y Souza realizaban una comparación significativa: los documentos de marketing a los que tuvimos acceso indican que la campaña de F.Collor, festejada como el máximo de sofisticación tecnológica, parecería hoy una de aficionados (p.18) (la traducción es nuestra).

(7) Siete caravanas recorrieron 266 poblaciones del interior de 23 estados, a lo largo de 103 dias (VV. AA., 1994). Estas caravanas recibieron mínima atención y valoración negativa por la mayoría de los medios de comunicación. 
de la inflación". Las dos principales organizaciones empresariales del pais, la Federaçao das Industrias do Estado de Sao Paulo (FIESP) y la Confederaçao Nacional de Industrias (CNI) pactaron su renuncia a subir los precios hasta el 31 de diciembre, condicionando su apoyo a la petición de cambios en las medidas tributarias y arancelarias. Tampoco los grandes bancos protestaron ante el congelamiento por parte del gobierno de la remuneración de los títulos de deuda pública (2.500 millones de dólares en la última quincena de junio) en las vísperas del plan, postergando su reclamación jurídica para después de las elecciones (8).

Los gastos de campaña son un dato elocuente del apoyo de las élites económicas a la candidatura de Fernando Henrique Cardoso, que gastó, oficalmente, 34 millones de reales frente a los 3,4 gastados por Lula. Esta diferencia es más significativa aún si tenemos en cuenta que en la campaña de F.H.C. las contribuciones de entidades privadas significaron el $99,9 \%$ de sus fondos, mientras que en la de Lula este tipo de aportación constituía el $41 \%$ del total. las aportaciones de personas físicas constituyeron el $1 \%$ de la campaña de F.H.C., mientras que para la de Lula estas aportaciones individuales sumaban más de un tercio de los fondos disponibles. La banca contribuyó con más de 10 millones de reales para F.H.C. (alrededor del $30 \%$ de su disponible), mientras que para Lula cedían 680.000 reales $(20 \%$ del monto total de campaña) (9).

La parcialidad de los medios de comunicación, y especialmente de la televisión, fue una constante de la campaña. Un estudio de la Universidad de Brasilia sobre los espacios políticos de la Rede Globo, principal empresa privada de comunicaciones, arroja datos expresivos sobre el bombardeo propagandistico (10). El ministro Ricúpero en los 153 días que duró su mandato tuvo 471 apariciones televisivas (3 diarias) para comentar las medidas económicas tomadas; además convocó 10 entrevistas de radio y televisión en emisión única nacional y participó en 5 programas especiales de entrevistas. Entre octubre del 93 y enero del 94 se emitieron 56 reportajes sobre Fernando Henrique Cardoso (todos ellos favorables), 18 sobre Lula (de ellos seis favorables y doce negativos), así como 18 sobre sindicalismo (todos negativos). Se fue creando una situación en la cual quien cuestionase el Plan Real, era convertido en partidario de la inflación. Como planteó Pinheiro (1995), el control de la mass media por las oligarquías políticas ponen en jaque los requisitos mínimos de transparencia que exige el proceso democrático (11).

Por otra parte, este bombardeo publicitario enmascaró la arbitrariedad de los poderes públicos. En particular la justi-

(8) La presentación de la cuenta de resultados de 1994 de los 15 mayores bancos muestra que, a partir de la entrada en vigor del Real, en el segundo semestre del ejercicio, sus beneficios aumentaron un 133 por ciento respecto al primero. Ver Folha de Sao Paulo (5/2/1995, p.II-12).

(9) Las aportaciones empresariales hablan por sí solas: el banco BRADESCO donaba 2,4 millones de reales (el cambio sigue siendo cuasi paritario con el dólar) a F.H.C. y nada a Lula; la empresa Vorantim cedía 1,67 millones y 100.000 respectivamente; el Itaú daba 1,68 millones al tucano y 500.000 al petista, convirtiéndose con diferencia en el mayor donante del Prácticas Tuteladas. Estos datos forman parte del informe presentado por el Departamento Intersindical de Asesoría Parlamentaria (DIAP), publicados por Zero Hora (Porto Alegre, 25/2/96, p. 4).

(10) Ver Veja, 14/9/94, p.39.

(11) La situación de oligopolio de los medios de comunicación en Brasil es patente si tiene en cuenta que 9 familias detentan 68 de las 71 concesiones de televisión, con 5.000 repetidores. Por otra parte, es sintomático que 137 parlamentarios conservadores poseen 17 periódicos, 29 cadenas de televisión y 91 radios (Lima 1991). cia electoral mostró en la mayoría de sus actuaciones una disposición poco decidida en casos graves como la investigación sobre el propio caso Ricúpero; sobre los pagos indebidos del ex-gobernador de Ceará, y ministro de Hacienda en funciones en el momento de la denuncia, Ciro Gomes (PSDB); en la repetición de las elecciones en el Estado de Rio de Janeiro, sin profundizar las investigaciones, única vía para el seguimiento judicial de los responsables del fraude; la inhibición mostrada para investigar los graves indicios de fraude en el estado de Bahía, denunciada por el propio PSDB regional (12).

A mediados de septiembre, dos semanas antes de las elecciones, cuando todo se sentía perdido en las filas petistas, Lula firmaba un no muy afortunado artículo en la revista Cambio 16 cuestionado la legitimidad de las elecciones y la modernidad de Brasil, lo que provocó un patriótico ataque de la opinión pública a su candidatura. La unanimidad de este ataque permitió al presidente Franco comentar con tono sarcástico que si eran ilegítimas, que no participase. A muchos nos trajo a la memoria el slogan con que la dictadura militar, en pleno apogeo del milagro económico de los años 70, hacía patente su prepotencia: "Brasil: ámalo o déjalo".

Como "actividad final de campaña electoral", el gobierno anunció extraoficialmente dos días antes de las elecciones, el descenso de los precios de los combustibles para el cuatro de octubre. El énfasis puesto por el Ministro de Hacienda, Ciro Gomes, en aclarar que era una medida para el día después de las elecciones, y por tanto no tenía carácter electoral, son ilustrativas de la tónica general que prevaleció entre el gobierno y la campaña de Cardoso.

\section{LOS RESULTADOS ELECTORALES}

En las elecciones del 3 de octubre, cerca de 78 millones de brasileños eligieron, además de la Presidencia de la República, las gobernaciones de los estados, los miembros de la Cámara Federal, de las Asambleas Legislativas regionales y se renovaron dos tercios del Senado.

En el sistema presidencialista la disputa se centra principalmente en el liderazgo personal de los candidatos, apoyados en su carisma, en su representatividad social y en sus propuestas programáticas. No obstante, en esta ocasión, con el Plan Real mediante, la disputa presidencial se convirtió en un plebiscito sobre la moneda. En cierta medida, ésta fue una campaña despolitizada dado que los programas de gobierno fueron marginados del debate electoral.

La dinámica específica de esta campaña ha trastocado sensiblemente el mapa político. En este sentido, se pueden realizar dos comentarios en relación a la influencia que la coalición electoral estructurada en torno al Plan Real ha te-

(12) Ante el Tribunal Superior Eleitoral, Ricúpero calificaba el episodio de la "parabólica" como una "invasión de privacidad", con anterioridad a ser nombrado embajador en Roma (Veja, 2/11/94). Ciro Gomes pagó con dinero público los viajes en avión y las estancias de los congresistas socialdemócratas en su convención de 1994. Tres años antes, el funcionario petista Edson Cardoni había sido condenado a 2 años y 8 meses por sufragar a través de una empresa estatal los gastos de un viaje en autobús, que líderes de movimientos sociales hacian a Brasilia (Veja, 14/9/1994). E tema del fraude electoral en Rio y los indicios encontrados en el estado de Bahía son tratados en diversos artículos de Veja (5/10/1994 y 19/10/1994). 
nido sobre los resultados electorales. En primer lugar, la alianza del PSDB con el PFL y el PTB ha ralentizado, en términos de correlación de fuerzas, una tendencia de crecimiento electoral de la izquierda más definida ideológicamente, que podía observarse desde el inicio de la transición (SOARES y D'ARAUJO, 1991). También en las elecciones se ha reforzado la hegemonía de la derecha no ya sólo porque esta táctica de coalición ha amortiguado su declive, sino también porque ésta ha implicado una derechización del partido socialdemócrata y, por tanto, el abandono de un importante espacio/puente de centro-izquierda.

En segundo lugar y relacionado con lo anterior, el Plan Real oscureció las elecciones legislativas, que estuvieron marcadas por el "adesismo" al real (13). Lo que probablemente haya aumentado el efecto arrastre que normalmente tiene la elección presidencial sobre el resto de cargos en disputa.

En el terreno puramente electoral, se pueden observar más signos de continuidad que de cambio.

Los resultados de la disputa presidencial, polarizada entre Fernando Henrique Cardoso y Lula, dos candidatos con una imagen alejada del político tradicional, siguen expresando la voluntad de transformación del electorado, ya puesta de manifiesto en 1989 (CUADRO I).

Cuadro I

RESULTADO ELECCIÓN PRESIDENCIAL

\begin{tabular}{lrr}
\hline Candidatos/Partidos & \multicolumn{1}{l}{ Votos } & Porcentaje \\
\hline F. H. Cardoso (PSDB) & 34.377 .198 & 54.28 \\
L. I. Lula da Silva (PT) & 17.126 .291 & 27.04 \\
Eneas Carneiro (PRONA) & 4.672 .026 & 7.38 \\
Orestes Quércia (PMBD) & 2.773 .779 & 4.38 \\
Leonel Brizola (PDT) & 2.016 .386 & 3.18 \\
Espiridiao Amín (PPR) & 1.740 .210 & 2.75 \\
Otros & 626.250 & 0.99 \\
Votos nulos & 7.193 .917 & 9.2 \\
Votos nulos & 7.445 .605 & 9.5 \\
Abstención & 16.820 .734 & 17.7 \\
Total de votos & 77.971 .676 & 100.0 \\
\hline
\end{tabular}

Fuente: Tribunal Superior Electoral.

La lógica diferenciada que anima las diferentes disputas electorales se hace evidente con la sonada derrota de los candidatos de los grandes partidos o líderes históricos de la talla de Orestes Quercia (PMDB), Leonel Brizola (PDT) o Espiridiao Amín (PPR). Habiendo conseguido sus partidos representación en la Cámara como para ser considerados grandes (más de 81 diputados) o medios (de 31 a 80 diputados), ellos no superaron el 5 por ciento de los votos.

El debilitamiento de los liderazgos históricos de los grandes partidos en la disputa presidencial puede estimular dos tipos de movimientos: las iniciativas de renovación intrapartidaria y la fuga de diputados de estos partidos hacia los gubernamentales. Como vimos, en los primeros meses de la nueva legislatura, este último es el más visible (14).

(13) El "adesismo" hace referencia a la estrategia que se observa sobre todo en la disputa proporcional, en la que los candidatos se "suman" al éxito del proyecto puesto en marcha por los diferentes ejecutivos, sean o no del mismo partido; en sus discursos y/o publicidad destacan las labores de articulación o apoyo parlamentario prestados como claves para el éxito de dicha medida.

(14) La primera tendencia la ilustra el cuestionamiento que sufre el liderazgo de
Las elecciones proporcionales muestran que el perfil del Congreso sigue siendo altamente fragmentado (18 partidos tienen representación en la Cámara). Según la tipología propuesta por RODRIGUES (1995), esta fragmentación ha sido débilmente modificada en relación a la anterior legislatura. Se mantienen los dos grandes partidos (con más de 81 diputados: PMDB y PFL); al igual que los seis partidos de porte medio, que aumentan su número de escaños (de 31 a 80 diputados: PT, PDT, PSDB, PP, PPR, PTB); perviven los partidos pequeños (de 10 a 30 diputados: PSB, PC do B y PL); mientras el número de micropartidos declina lentamente, pasando de ocho a siete (ver CUADRO II y anexo).

\section{Cuadro II \\ EVOLUCIÓN DE LA COMPOSICIÓN DE LA CÁMARA FEDERAL (1986-1994)}

\begin{tabular}{|c|c|c|c|c|}
\hline \multirow[t]{2}{*}{ Partido } & $\begin{array}{l}\text { Elección } \\
\text { de } 1986\end{array}$ & $\begin{array}{c}\text { Fin Legis. } \\
1986\end{array}$ & $\begin{array}{c}\text { Elección } \\
\text { de } 1990\end{array}$ & $\begin{array}{l}\text { Elección } \\
\text { de } 1994\end{array}$ \\
\hline & $\begin{array}{l}\text { Escaños } \\
\text { Porcent. }\end{array}$ & $\begin{array}{l}\text { Escaños } \\
\text { Porcent. }\end{array}$ & $\begin{array}{l}\text { Escaños } \\
\text { Porcent. }\end{array}$ & $\begin{array}{l}\text { Escaños } \\
\text { Porcent. }\end{array}$ \\
\hline \multirow[t]{2}{*}{ PMBD } & 257 & 131 & 108 & 107 \\
\hline & 52.9 & 26.5 & 21.6 & 20.9 \\
\hline \multirow[t]{2}{*}{ PFL } & 118 & 90 & 84 & 89 \\
\hline & 24.2 & 18.2 & 16.7 & 1.3 \\
\hline \multirow[t]{2}{*}{ PDT } & 24 & 38 & 47 & 34 \\
\hline & 4.9 & 7.7 & 9.3 & 6.6 \\
\hline \multirow[t]{2}{*}{ PDS } & 33 & 32 & 42 & - \\
\hline & 6.8 & 6.5 & 8.3 & - \\
\hline \multirow[t]{2}{*}{ PP } & - & - & - & 37 \\
\hline & - & - & - & 7.2 \\
\hline \multirow[t]{2}{*}{ PRN } & - & 31 & 40 & 1 \\
\hline & - & 6.3 & 8.0 & 0.2 \\
\hline \multirow[t]{2}{*}{ PTB } & 18 & 28 & 38 & 31 \\
\hline & 3.7 & 5.7 & 7.5 & 6.1 \\
\hline \multirow[t]{2}{*}{ PSDB } & - & 60 & 37 & 62 \\
\hline & - & 12.1 & 7.4 & 12.1 \\
\hline \multirow[t]{2}{*}{ PPR } & - & - & - & 52 \\
\hline & - & - & - & 10.1 \\
\hline \multirow[t]{2}{*}{ PT } & 16 & 17 & 35 & 49 \\
\hline & 3.3 & 3.4 & 6.9 & 9.6 \\
\hline \multirow[t]{2}{*}{ PDC } & 5 & 15 & 22 & - \\
\hline & 1.0 & 3.0 & 4.4 & - \\
\hline \multirow[t]{2}{*}{ PL } & 6 & 13 & 15 & 13 \\
\hline & 1.2 & 2.6 & 3.0 & 2.5 \\
\hline \multirow[t]{2}{*}{ PSB } & 1 & 8 & 11 & 14 \\
\hline & 0.2 & 1.6 & 2.2 & 2.7 \\
\hline \multirow{2}{*}{ PSC } & - & 3 & 6 & 3 \\
\hline & - & 0.6 & 1.2 & 0.6 \\
\hline \multirow[t]{2}{*}{ PCdoB } & 6 & 6 & 5 & 10 \\
\hline & 1.2 & 1.2 & 0.9 & 1.9 \\
\hline \multirow[t]{2}{*}{ PRS } & - & 7 & 4 & - \\
\hline & . & 1.4 & 0.8 & - \\
\hline \multirow{2}{*}{ PPS (exPCB) } & 3 & 3 & 3 & 2 \\
\hline & 0.6 & 0.6 & 0.6 & 0.4 \\
\hline \multirow[t]{2}{*}{ PTR } & - & 4 & 2 & - \\
\hline & - & 0.8 & 0.4 & - \\
\hline \multirow[t]{2}{*}{ PST } & - & 5 & 2 & - \\
\hline & - & $1-0$ & 0.4 & . \\
\hline \multirow[t]{2}{*}{ PSD } & - & 1 & 1 & 3 \\
\hline & - & 02 & 0.2 & 0.6 \\
\hline PRP & - & 1 & - & 1 \\
\hline & - & 0.2 & . & 0.2 \\
\hline PT do B & - & 1 & - & - \\
\hline & - & 0.2 & - & - \\
\hline PMN & - & 1 & 1 & 4 \\
\hline & - & 0.2 & 0.2 & 0.8 \\
\hline PV & - & - & - & 1 \\
\hline & - & - & - & 0.2 \\
\hline TOTAL & 487 & 495 & 503 & 513 \\
\hline & 100.0 & 100.0 & 100.0 & 100.0 \\
\hline
\end{tabular}

Fuente: Rodrigues 1995.

O.Quercia en PMDB. La segunda la deja claro el crecimiento del partido socialdemócrata en los primeros meses de 1995. 
En términos de evolución de la correlación de fuerzas se confirma el crecimiento de la izquierda y el centro-izquierda representado por el PSDB. El partido que más crece en la Cámara es el PT al pasar de 35 a 49 diputados (y de un senador a cinco, al tiempo que empieza su andadura en dos gobernaciones). El 35 por ciento de los votos en la sigla del partido, en un sistema de listas abiertas como el brasileño, evidencia que su electorado es uno de los más politizados al reforzar al partido en su conjunto e no fomentar la lógica de la competición interna de sus candidatos. El PSDB aumenta su bancada de 37 a 62 diputados, conserva sus diez senadores, aunque aumenta considerablemente su poder en la Cámara gracias a las seis gobernaciones conseguidas (destacan Sao Paulo, Minas Gerais y Rio de Janeiro), que suman el 51,3 por ciento del electorado del país, y bastante más de la mitad del producto interior bruto.

Por otra parte, merece destacarse la aparición en la escena electoral de un vector de rasgos antipolíticos, que se refleja en el tercer puesto obtenido por Eneas Carneiro en la disputa presidencial y la gran cantidad de votos nulos y blancos. Si bien es verdad que la obligatoriedad del voto relativiza el contenido de protesta de los nulos y blancos, los cuatro millones y medio de votos obtenidos con un mensaje de orden y moralización (más trabajo, y menos política) son un indicador consistente de la presencia de este vector antipolítico (Lima y Bustani, 1995). Que su Partido da Reconstruccao da Ordem Nacional (PRONA) no haya conseguido representantes en la Cámara, si bien puede ser interpretado como una ilustración de la lógica dispareja que acompaña las elecciones simultáneas. también es un indicador de la cultura política antiparlamentaria de los votantes pronistas (15)

Por lo tanto, en estas elecciones se vuelve a confirmar la voluntad de cambio por parte del electorado, tanto en los candidatos presidenciales como en la alta renovación que ha vivida la Cámara, en línea con las tendencias electorales observadas en disputas pasadas _el moderado crecimiento de fuerzas de centro-izquierda e izquierda-. Además, en términos de correlación de fuerzas, la coalición gubernamental de Cardoso tiene garantizada la mayoría en el ámbito legislativo, aunque no se puede olvidar la heterogeneidad de la base política de este gobierno.

\section{CONCLUSION}

La compleja relación de fuerzas en el interior de la coalición victoriosa se reflejó en los primeros meses de gobierno con el aumento de las presiones procedentes de los sectores más retrógrados del congreso brasileño, que evidencian el alto grado de dependencia del gobierno (16).

(15) El alto porcentaje de nulos y blancos, así como el de abstención siendo el voto obligatorio, tiene que ver con el problema antes mencionado de inteligibilidad. La papeleta de voto presidencial está separada de la otra que agrupa las demás cargos en disputa - en la que conviven mayoritarios y proporcionales, exigiendo éstos últimos que el elector escriba el nombre completo o número de registro de su candidato. A este problema estructural se añade uno coyuntural ya mencionado: las elecciones simultáneas tienen como efecto que la disputa presidencial margina las proporcionales, más en esta ocasión si se tiene en cuenta el efecto despolitizador del Real.

(16) Comparando los primeros meses de gobierno con los de los anteriores presidentes, Cardoso mostró una acelerada caída de los índices de popularidad: del 70 por ciento en diciembre de 1994 al 36 por ciento en enero del 95 (Veja, 8/2/95).
La adaptación a las tradicionales formas de hacer política que viene mostrando el presidente Cardoso juega contra de la posibilidad de jerarquizar objetivos y direccionar políticamente la acción de gobierno en un sentido reformista (17).

Celso Furtado toca el núcleo del problema de la modernización cuando afirma que se está simplicando la realidad si se plantea la cuestión de la reforma del Estado como una cuestión de naturaleza administrativa y no política (18).

Si a esta problemática de la continuidad de estilos de hacer política añadimos la escasa sensibilidad del nuevo gobierno hacia a cuestión social, vemos que las esperanzas depositadas por la opinión pública en el gobierno socialdemócrata pueden verse frustradas. La aprobación por parte del Congreso de un aumento del 100 por ciento del salario de los parlamentarios, ministros, y del propio Presidente, que se acordó en la misma semana en la que el gobierno se proponía vetar la propuesta de aumento para Rl\$100 del salario mínimo, argumentando que esto aumentaría el consumo y podría generar inflación, puso de manifiesto la poca atención que gobierno presta a los costes sociales del ajuste

Al mismo tiempo, el gobierno Cardoso ha puesto en marcha de forma acelerada, sin discusión alguna con los sectores sociales organizados, el proceso de reforma de la seguridad social y las privatizaciones del sector eléctrico, de las telecomunieaciones y del petróleo. La poca visibilidad y transparencia del proyecto de privatizaciones, alimenta la incertidumbre general de la actual coyuntura brasileña, y ha motivado una considerable polémica en la opinión pública y una fuerte oposición de los sectores sindicales directamente afectados por el proceso (19).

Se teme que la propuesta de "gobierno pendular", manejada durante la campaña por muchos intelectuales que apoyaban a Cardoso para justificar la peculiar alianza política, está lejos de verse cumplida: la por ahora postergada vertiente "socialdemócrata" del programa de reformas se ve sometida por un ajuste que se desarrolla en los parámetros estipulados en el Consenso de Washington.

\section{ANEXO PARTIDOS}

\section{IZQUIERDA}

Partido dos Trabalhadores (PT). Surge en 1980, vinculado a la creciente movilización social que se da a lo lar-

(17) Esto se hizo evidente en la amnistía concedida al senador H.Lucena, que tenía su nuevo mandato electoral pendiente de sentencia de la Justicia Federal debido a que utilizó de forma gratuita la gráfica del Senado para publicación de su propaganda electoral privada durante la pasada campaña. Este tipo de negociaciones se puso también de manifiesto cuando el grupo ruralista (suprapartidario) prestó sus 140 votos a la aprobación del programa de privatizaciones sólo después que el gobierno se dispusiese a bajar los tipos de interés del crédito agrícola (Folha de Sao Paulo, 29/5/95). Además, actualmente, el gobierno también se muestra dispuesto a negociar apoyos para la reforma constitucional a cambio de modificar la demarcación de los territorios indígenas contemplados en la Constitución de 1988 (ver artículo del Conselho Indigenista Misionario en el Jornal da Ciencia Hoje, n.0324, p.8, junio del 95).

(18) "0 paradoxo dos palanques", Folha de Sao Paulo (18/9/95).

(19) Un ejemplo de esta resistencia fue la huelga de los sindicatos petroleros en el segundo trimestre de 1995: finalizó con la ocupación de refinerías estratégicas por parte del Ejército. 
go del proceso de transición, en particular, a la renovación que vive el movimiento sindical.

Partido Socialista Brasileño (PSB). Fundado en 1947, no supo ocupar el lugar dejado por la ilegalización del PCB en ese período. Desaparecido en 1965, fue refundado en 1986.

Partido Popular Socialista (PPS). Es el nuevo nombre del Partido Comunista. Fundado en 1922, vivió en la ilegalidad durante casi toda su existencia - excepto en el período 1945-47-, hasta su legalización en 1985.

Partido Comunista do Brasil (PCdoB). Surge de una disidencia del PCB surgida en 1958, de línea estalinista-maoísta-albanesa, mantiene núcleos de militancia junto a movimientos sociales en zonas deprimidas.

Partido Verde (PV). Surgido de las inquietudes ecológicas de las clases medias politizadas, tiene implantación casi exclusiva en Rio de Janeiro y está estrechamente ligado a la figura de su fundador, Fernando Gabeira.

\section{CENTRO-IZQUIERDA}

Partido da Social Democracia Brasileña (PSDB). Creado en 1988 por parlamentarios oriundos del PMDB, a raíz de conflictos de liderazgo y las tensiones generadas en el interior de ese grupo parlamentario durante las votaciones del proceso constituyente.

Partido Demócratico Trabalhista (PDT). Partido heredero de las corrientes populistas de izquierda y sindical agrupadas en el Partido Trabalhista Brasileiro antes del golpe del 64, está estrechamente ligado al carisma de su líder histórico, Leonel Brizola.

\section{CENTRO-DERECHA}

Partido do Movimento Democrático Brasileiro (PMDB). Sucesor del MDB, que cobijó a las diversas oposiciones durante la etapa bipartidista impuesta por el Acta Institucional n. ${ }^{\circ} 5$ de 1966, durante el período militar. A pesar de las múltiples escisiones que ha sufrido después de la entrada en vigor de la Ley de Partidos Políticos (1979), continúa siendo el mayor partido en la Cámara.

\section{DERECHA}

Partido da Frente Liberal (PFL). Surge de una escisión del Partido Demócrata Social (PDS) (heredero de la oficialista ARENA), ante la elección de sucesor de Figuereido, ante el liderazgo conflictivo de Paulo Maluf. Su perfil de partido progubernamental — que su razón de ser es participar en el ejecutivo o apoyarlo, en la medida en que éste garantiza los recursos para su existencia como organización- le garantiza buenos resultados electorales, sobre todo en el nordeste.

Partido Progresista Reformador (PPR). Es producto de la unión, en mayo de 1993, del PDS - heredero de ARENA - con el Partido Demócrata Cristiano (PDC), li- gado a la figura carismática de $\mathrm{P}$. Maluf, de rasgos (neo)liberales autoritarios. En el momento de su lanzamiento llegó a contar con 72 diputados.

Partido da Reconstruçao Naoional (PRN). Partido surgido dentro del congreso para viabilizar la candidatura de Collor de Mello en 1989. Después del impeachment está condenado a ser una "sigla de alquiler".

Partido Trabalhista Brasileiro (PTB). Es una sigla surgida de la mano de G. Vargas en 1945 dentro de su estrategia de coopatción de las masas trabajadoras, fue extinto en 1965, después de haberse hecho más nítido su perfil sindicalista izquierdista con Leonel Brizola. En 1979, la sigla fue disputada por éste y por I. Vargas, siendo esta última quien ganó el pleito ante la Justicia Electoral. Su perfil es progubernamental.

Partido Liberal (PL). Es una escisión del PFL encabezada por el diputado Antonio Valle, que gana visibilidad en la constituyente. Tiene sus bases en la zona sur y sudeste. Mantiene estrechas relaciones con el PPR en el gobierno de la ciudad de Sao Paulo.

Partido Progresista (PP). Surgido en 1993 por la unión del Partido Social Trabalhista (PST) y del Partido Trabalhista Renovador (PTR), con el objetivo de ser un partido proguhernamental. Contaba con 37 diputados y cuatro senadores al formarse en el Congreso. Se autodefine como socialdemócrata.

Partido Social Cristiano (PSC), Partido Social Democrático (PSD), Partido Reformista Popular (PRP) y Partido da Mobilizaçao Nacional (PMN). Estos pequeños partidos, de implantación local o regional, logran su presencia en la cámara vía coaliciones y no pretenden más que realizar una política de composición que les garantice su supervivencia.

\section{BIBLIOGRAFIA}

DimensteIn, G. Y SouZA, J. (1994): A Historia Real. Trama de uma sucessao, Sao Paulo, Ed. Atica/Folha de Sao Paulo.

Gugliano, A. A.: "El partido dos Trabalhadores, la elección presidencial y el futuro de Brasil", ponencia presentada en el seminario "Partidos Políticos y Modernización en América Latina", Tribuna Americana, Casa de la Américas, Madrid, julio de 1994.

LiMA, N. (1991): " O cuarto poder nas maos da política", Imprensa $\mathrm{n}^{\circ} 52$.

LiMA, M. O. C y Bustani, C. (1995): "The brazilian elections of 1994", Electoral Studies, n. ${ }^{\circ} 2$.

JEREZ, A. (1995): "Brasil: intelectuales y socialdemocracia", El Viejo Topo, n. 87.

MAINWARING, S.: "Partidos, políticos e sistemas eletorais", Novos Estudos, n. ${ }^{\circ} 29,1991$.

MAINWARING, S. (1993): "Democracia presidencialista multipartidaria: o caso do Brasil", Lua Nova, n. ${ }^{\circ} 28 / 29$.

PECAUT, Daniel (1990): Os intelectuais e a política no Brasil, Sao Paulo Ed. Atica.

PEREIRA, L. C. BRESSER (1994): “A economía e a política do Plano Real", Revista de Economía Política, n. ${ }^{\circ} 4$. 
Plano F. H. CARDoso (1994): "Exposiçao de motivos n. 395 (17 de diciembre de 1993)", Revista de Economía Política, n. $^{\circ} 2$.

RODRIGUES, L. M.: "Eleiçoes, fragmentaçao partidaria e governabilidade", Novos Estudos, n. ${ }^{\circ} 41,1995$.
SoARes, G. A. Dillon Y D'Araujo M. C. (1991): “Los mitos de la presna y las elecciones de 1990", Revista de Estudios Políticos, n. $^{\circ} 71$.

VV. AA: Viagem ao coraçao do Brasil, Scritta, 1994.

\section{RESUMEN}

En este artículo, los autores analizan los aspectos más característicos de la última campaña electoral en Brasil y los resultados de los comicios que llevaron a Fernando Henrique Cardoso a la Presidencia. De ese análisis se derivan conclusiones sobre el panorama político resultante y la transformación en la relación de fuerzas entre partidos y al interior de los mismos. Finalmente, se apuntan las líneas principales de la acción de gobierno del nuevo Presidente.

\section{ABSTRACT}

In this article, the authors analyze the more characteristics aspects of the last electoral campaign in Brazil and the electoral results with the triumph of F.H. Cardozo. From this analysis, they extract conclusions about the political situation and the transformation of balance of power among parties and inside them. Finally, they set the main lines of governmental action of the new President. 